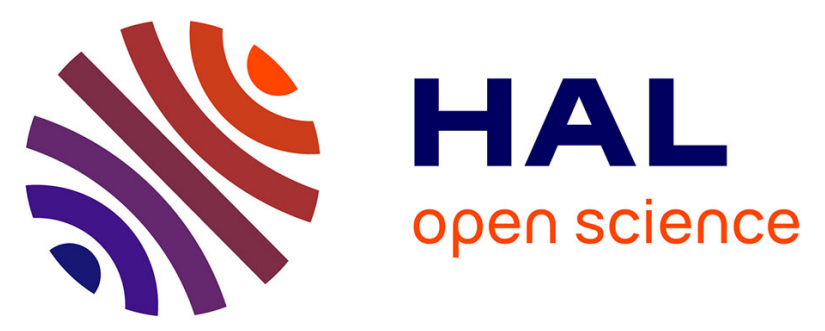

\title{
Thermo-oxidation behaviour of composite materials at high temperatures: A review of research activities carried out within the COMEDI program
}

Marie Christine Lafarie, Jean-Claude Grandidier, M. Gigliottia, Loic Olivier, Xavier Colin, Jacques Verdu, Jacques Cinquin

\section{To cite this version:}

Marie Christine Lafarie, Jean-Claude Grandidier, M. Gigliottia, Loic Olivier, Xavier Colin, et al.. Thermo-oxidation behaviour of composite materials at high temperatures: A review of research activities carried out within the COMEDI program. Polymer Degradation and Stability, 2010, 95 (6), pp.965-974. 10.1016/j.polymdegradstab.2010.03.019 . hal-02456273

\section{HAL Id: hal-02456273 \\ https://hal.science/hal-02456273}

Submitted on 27 Jan 2020

HAL is a multi-disciplinary open access archive for the deposit and dissemination of scientific research documents, whether they are published or not. The documents may come from teaching and research institutions in France or abroad, or from public or private research centers.
L'archive ouverte pluridisciplinaire HAL, est destinée au dépôt et à la diffusion de documents scientifiques de niveau recherche, publiés ou non, émanant des établissements d'enseignement et de recherche français ou étrangers, des laboratoires publics ou privés. 


\title{
Thermo-oxidation behaviour of composite materials at high temperatures: A review of research activities carried out within the COMEDI program
}

\author{
M.C. Lafarie-Frenot ${ }^{\mathrm{a}}$, J.C. Grandidier ${ }^{\mathrm{a}}$, M. Gigliotti ${ }^{\mathrm{a}, *}$, L. Olivier ${ }^{\mathrm{a}}$, X. Colin ${ }^{\mathrm{b}, 1}$, J. Verdu ${ }^{\mathrm{b}, 1}$, J. Cinquin $^{\mathrm{c}}$ \\ a Institut Pprime, CNRS - ENSMA - Université de Poitiers, Département Physique et Mécanique des Matériaux, ENSMA - Téléport 2 - 1, Avenue Clément Ader, \\ BP 40109, F86961 Futuroscope Chasseneuil Cedex, France \\ ${ }^{\mathrm{b}}$ Arts et Metiers ParisTech - Laboratoire PIMM, 151 Boulevard de l'Hôpital, 75013 Paris, France \\ ${ }^{\mathrm{c}}$ EADS IW, 12 Rue Pasteur, 92152 Suresnes, France
}

Keywords:

Polymer-matrix composites (PMCs)

\section{Durability}

Thermo-oxidation

Multi-scale modelling

Optical microscopy

\begin{abstract}
A B S T R A C T
The present paper presents a review of the main activities carried out within the context of the COMEDI research program, a joint collaboration involving three research teams focusing on the thermo-oxidation behaviour of composite materials at high temperatures.

The scientific aim of the COMEDI research program was to better identify the link between the physical mechanisms involved in thermo-oxidation phenomena: oxygen reaction-diffusion, chemical shrinkage strain/stress, degradation at different scales and to provide tools for predicting the thermo-oxidation behaviour of composite materials under thermo-oxidative environments including damage onset.

This aim was accomplished by investigating experimentally the thermo-oxidation behaviour of pure resin samples - both industrial and "model" materials - and by interpreting the results by a coupled reaction-diffusion-mechanics multiphysics model.

A dedicated numerical model tool has been developed and implemented into the ABAQUS ${ }^{\circledR}$ finite element commercial software. This tool was employed to simulate the thermo-oxidative behaviour of a fibre-matrix microscopic representative composite cell.

Finally, the model predictions for the composite have been validated by comparing the experimental and the simulated local matrix shrinkage displacements and the mass loss of composite specimens.
\end{abstract}

\section{Introduction}

The use of carbon fibre reinforced polymer (CFRP) laminated composites is rapidly increasing. However much research is still needed in order to enlarge the application range of such materials, in particular to enable such materials to work at relatively high temperatures (lower than their glass transition temperatures, $T_{\mathrm{g}}$ ).

The COMEDI research program - a joint collaboration involving three research teams, EADS IW, ENSMA Poitiers and Arts et Métiers Paris - was built in order to achieve such a goal. "Hot" structures for helicopters and aircraft structures are subjected to severe thermomechanical solicitations and to long-term superposition of mechanical cyclic loading, thermo-oxidative ageing, thermal fatigue.

Some studies [1-3] carried out on unidirectional polymermatrix composites have shown that thermal ageing leads to thermo-oxidative degradation of the matrix. However this

\footnotetext{
* Corresponding author. Tel.: +330549 49 8340; fax: +330549498238.

E-mail address: marco.gigliotti@lmpm.ensma.fr (M. Gigliotti).

1 Tel.: +331442464 13; fax: +33144246382.
}

phenomenon is generally confined to areas directly exposed to the environment, while no significant degradation is found far from the external surfaces. These observations have been confirmed by other research studies [4], which also show the anisotropic thermooxidation behaviour of the composite; usually, oxygen diffusion is faster along the fibres.

Concerning the prediction of the thermo-mechanical behaviour of composite materials under oxidizing environment, the literature presents some modelling attempts for "high temperature", thermally-stable composites and PMR-15 resins [5-8].

Previous studies [9] on composite laminates have also shown that thermo-oxidation may lead to consistent chemical shrinkage induced matrix strains and matrix cracks on the external edges of samples in contact with the environment.

Diffusion controlled oxidation phenomena play a central role in these degradation mechanisms, leading to density increase and mass loss. Resulting local chemical shrinkage strains and stresses may lead to "spontaneous" cracking [10]. Damage in carbon-epoxy composites exposed to air at high temperatures is partly due to thermo-oxidation induced embrittlement of the matrix surface layers. 
A mechanistic coupled diffusion-reaction oxidation model has been developed and identified for carbon-epoxy and carbon-bismaleimide composites [11]. This model predicts mass loss and thermo-oxidation induced matrix shrinkage in pure resins and UD composites [12], but does not include coupling with mechanics.

At the start of the COMEDI program the mechanisms of thermooxidation were clearly identified, but the existence of coupling between oxidation and local stress state was only suspected [13].

Some theoretical research concerning the 'multiphysics' modelling of reaction-diffusion-mechanics has been published even though still not adequately compared to experiments [14]. Moreover, in the case of composite laminates, the local state of stress is highly dependent on the multi-scale structure of the laminate (fibre, matrix, unidirectional ply, stacking sequence, edge effects, anisotropy...). Finally, none of the available approaches is able to predict the onset of cracking which seems to depend strongly on the interaction between different physical mechanisms besides ageing.

The scientific aim of the COMEDI research program was:

- to better identify the link between the physical mechanisms involved in thermo-oxidation phenomena: oxygen reaction-diffusion, chemical shrinkage strain/stress, degradation... at different scales: microscopic scale (fibre-matrix), mesoscopic scale (the unidirectional ply in contact with the environment).

- to provide tools for predicting the thermo-oxidation behaviour of composite materials under thermo-oxidative environment including damage onset.

The approach was, initially, to characterise and understand the mechanisms of thermo-oxidation of the epoxy matrix alone, without and with mechanical stress. Pure resin samples were manufactured both industrial (an industrial composite material made from carbon fibre and epoxy formulation selected by EADS IW) and "model" materials - and their response to the thermo-oxidation analyzed. Their behaviour was then interpreted by a coupled reaction-diffusion-mechanics multiphysics model. To identify the values of certain parameters of the model and the intensity of the couplings occurring between different physical processes, a specific test setup - the COMEDI oxidative chambers - has been designed and manufactured. This setup also allows performing accelerated ageing tests under pure oxygen environments.

In a second step, a dedicated numerical model tool has been developed and implemented into the ABAQUS ${ }^{\circledR}$ finite element commercial software. This tool was employed to simulate the thermo-oxidative behaviour of a fibre-matrix microscopic representative composite cell.

Finally, the model predictions for the composite have been validated by comparing the experimental and the simulated local matrix shrinkage displacements and the mass loss of composite samples. References [15-18] present some published partial results from the COMEDI research program, in which some further details about the work activity can be found.

\section{Coupled diffusion-reaction-mechanics model}

In order to simulate the local changes induced by the thermooxidation in the polymer matrix, the evolution of chemical reactions at each point in space at any time and the coupling between oxygen reaction-diffusion and mechanics should be modelled. The joint action of the LIM-ENSAM and of the LMPM-ENSMA research departments has developed a comprehensive coupled model. The ultimate goal of such model is to predict the local thermo-oxidation induced shrinkage strain/stress in a composite material and the conditions that lead to damage onset and propagation.
The description of the chemical processes is based on the mechanistic scheme developed by PIMM-ENSAM [10-12]. Five different reactive species: $\mathrm{POOH}, \mathrm{PH}, \mathrm{P}^{\circ}, \mathrm{O}_{2}, \mathrm{PO}_{2}^{\circ}$, and two volatile species $\left(\mathrm{H}_{2} \mathrm{O}\right.$, and other organic volatile products, $\left.\mathrm{V}\right)$ are considered separately. The mechanistic scheme is based on a closed loop principle, since the overall chain reaction generates its own initiator (hydro peroxides $\mathrm{POOH}$ ). In the context of classical thermodynamics (near equilibrium) the coupling between oxygen reaction-diffusion and mechanics has been described in the following general form (see also references [16], [18]):

For mobile species:

$$
\begin{aligned}
& \frac{\mathrm{d} C}{\mathrm{~d} t}=-k_{2}\left[\mathrm{P}^{\cdot}\right] C+k_{6}\left[\mathrm{PO}_{2}^{\cdot}\right]^{2}+D_{\mathrm{O}_{2}} \nabla^{2} C+\beta_{\mathrm{O}_{2}} \nabla^{2}(\operatorname{tr} \mathbf{E}) \\
& \frac{\mathrm{d}[V]}{\mathrm{d} t}=v k_{1}[\mathrm{POOH}]+\beta_{V} \nabla^{2}(\operatorname{tr} \mathbf{E})
\end{aligned}
$$

$\frac{\mathrm{d}\left[\mathrm{H}_{2} \mathrm{O}\right]}{\mathrm{d} t}=k_{1}[\mathrm{POOH}]+\beta_{\mathrm{H}_{2} \mathrm{O}} \nabla^{2}(\operatorname{tr} \mathbf{E})$

where $C$ is the oxygen concentration.

In a first approach, the diffusion of volatile species has been neglected because of their low molecular weight. For non mobile species attached to the network diffusion is considered negligible which leads to:

$\frac{\mathrm{d}[\mathrm{POOH}]}{\mathrm{d} t}=k_{3}[\mathrm{PH}]\left[\mathrm{PO}_{2}^{\cdot}\right]-k_{1}[\mathrm{POOH}]$

$\frac{\mathrm{d}[\mathrm{PH}]}{\mathrm{d} t}=k_{3}[\mathrm{PH}]\left[\mathrm{PO}_{2}^{\cdot}\right]-\gamma k_{1}[\mathrm{POOH}]$

$\frac{\mathrm{d}\left[\mathrm{PO}_{2}^{\cdot}\right]}{\mathrm{d} t}=k_{2} C\left[\mathrm{P}^{*}\right]-k_{3}[\mathrm{PH}]\left[\mathrm{PO}_{2}^{\cdot}\right]-k_{5}\left[\mathrm{PO}_{2}^{\cdot}\right]\left[\mathrm{P}^{*}\right]-2 k_{6}\left[\mathrm{PO}_{2}^{\cdot}\right]^{2}$

$$
\begin{aligned}
\frac{\mathrm{d}\left[\mathrm{P}^{\bullet}\right]}{\mathrm{d} t}= & 2 k_{1}[\mathrm{POOH}]-k_{2} C\left[\mathrm{P}^{\bullet}\right]+k_{3}[\mathrm{PH}]\left[\mathrm{PO}_{2}^{\cdot}\right] \\
& -2 k_{4}\left[\mathrm{P}^{\bullet}\right]^{2}-k_{5}\left[\mathrm{P}^{\bullet}\right]\left[\mathrm{PO}_{2}^{\cdot}\right]
\end{aligned}
$$

$\frac{\mathrm{d}\left[\mathrm{PI}_{1}\right]}{\mathrm{d} t}=k_{4}\left[\mathrm{P}^{\cdot}\right]^{2} \quad \frac{\mathrm{d}\left[\mathrm{PI}_{2}\right]}{\mathrm{d} t}=k_{5}\left[\mathrm{P}^{*}\right]\left[\mathrm{PO}_{2}^{\cdot}\right] \quad \frac{\mathrm{d}\left[\mathrm{PI}_{3}\right]}{\mathrm{d} t}=k_{6}\left[\mathrm{PO}_{2}^{*}\right]^{2}$

The simultaneous solution of the above set of differential equations with the pertinent initial and boundary conditions (see details in references [16] and [18]) allows evaluating at any time and at any point some global quantities such as the mass loss due to the departure of volatile species and a global indicator of the progress of the chemical reaction, the global quantity of absorbed oxygen $\mathrm{Q}$ given by:

$Q(x, y, z, t)=\int_{0}^{t} R(C) \mathrm{d} t ; \quad R(C)=-\frac{\mathrm{d} C}{\mathrm{~d} t}$

As proposed in $[12,13]$, the matrix chemical shrinkage strain generated by thermo-oxidation induced mass loss can be expressed by the following relationship:

$$
\begin{aligned}
\mathbf{E}^{\mathrm{vch}} & =\left(\frac{\Delta m}{m_{0}}-\frac{\Delta \rho}{\rho_{0}}\right) \text { with } \frac{1}{m_{0}} \frac{\mathrm{d} m}{\mathrm{~d} t} \\
& =\frac{1}{\rho_{0}}\left(M_{\mathrm{O}_{2}} \frac{\mathrm{d} C}{\mathrm{~d} t}-M_{\mathrm{H}_{2}} \mathrm{O} \frac{\mathrm{d}\left[\mathrm{H}_{2} \mathrm{O}\right]}{\mathrm{d} t}-M_{\mathrm{v}} \frac{\mathrm{d}[V]}{\mathrm{d} t}\right)
\end{aligned}
$$


in which $M_{\mathrm{O}_{2}}, M_{\mathrm{H}_{2} \mathrm{O}}$ and $M_{\mathrm{v}}$ are the molar mass of $\mathrm{O}_{2}, \mathrm{H}_{2} \mathrm{O}$ and volatile products other than $\mathrm{H}_{2} \mathrm{O}$.

The mechanical behaviour of the material is represented by a non-linear viscoelastic law, which is based on the partition of stresses and strains in their deviatoric and spherical parts, respectively:

$$
\begin{aligned}
& \text { spherical part : } \operatorname{Tr} \boldsymbol{S}=3 K_{\mathrm{v}}(Q) \operatorname{tr} \boldsymbol{E}-3 K_{\mathrm{v}}(Q) \boldsymbol{E}^{\mathrm{vth}}-3 K_{\mathrm{v}} \\
& (Q) \boldsymbol{E}^{\mathrm{vch}}-3 \sum_{j=1}^{n} K_{\mathrm{j}}(Q) z_{\mathrm{j}}^{\mathrm{tr} E} \\
& \text { deviatoric part : } \boldsymbol{S}^{\mathrm{d}}=2 G_{\mathrm{v}}(Q) \boldsymbol{E}^{\mathrm{d}}-2 \sum_{j=1}^{m} G_{\mathrm{j}}(Q) z_{\mathrm{j}}^{E \mathrm{~d}} \\
& \text { internal variables : } \frac{\mathrm{d} z_{\mathrm{j}}^{\mathrm{tr} E}}{\mathrm{~d} t}=\frac{1}{a_{\mathrm{s}}(T) \tau_{\mathrm{j}}^{\mathrm{tr} E}}\left(z_{\mathrm{j}}^{\mathrm{tr} E}-K_{\mathrm{j}} \operatorname{tr} E\right) \\
& \qquad \frac{\mathrm{d} z_{\mathrm{j}}^{E \mathrm{~d}}}{\mathrm{~d} t}=\frac{1}{a_{\mathrm{s}}(T) \tau_{\mathrm{j}}^{E \mathrm{~d}}}\left(z_{\mathrm{j}}^{E \mathrm{~d}}-G_{\mathrm{j}} \operatorname{tr} \boldsymbol{E}^{\mathrm{d}}\right)
\end{aligned}
$$

where $\boldsymbol{S}$ is the stress tensor, $\boldsymbol{E}$ the strain tensor (the index $d$ refers to the deviatoric part of the tensor). The internal variables describing the viscoelastic behaviour are denoted $z_{j}^{\text {trE }}$ for the spherical part and $\boldsymbol{z}_{\mathbf{j}}^{\mathrm{Ed}}$ for the deviatoric part. The parameters are the moduli $K_{\mathrm{v}}(Q), G_{\mathrm{v}}(Q), K_{\mathrm{j}}(Q), G_{\mathrm{j}}(Q)$, the coefficients of the viscoelastic distribution $\left(\tau_{\mathrm{j}}\right)$ and the temperature shift functions, $a_{\mathrm{s}}(T)$ and $a_{\mathrm{d}}(T)$.

It should be noted that in equations (11) coupling between chemistry and mechanics is achieved through the presence of the matrix chemical shrinkage strain within the constitutive mechanical law of the polymer material and the dependency of the material moduli $\left(K_{\mathrm{v}}(Q), G_{\mathrm{v}}(Q), K_{\mathrm{j}}(Q), G_{\mathrm{j}}(Q)\right)$ on the concentration of oxidation products, $Q$, which expresses the thermo-oxidation induced mechanical behaviour changes of the oxidized resin. This last form of chemo/mechanics coupling is sometimes referred as indirect.

The main difficulty in evaluating the changes in mechanical properties induced by oxidation using standard tests is inherent to the oxygen reaction/diffusion phenomenon, which does not allow oxidizing uniformly samples that are relatively thick. These changes can be appreciated, for instance, by employing local elastic indentation module measures all along the oxidized zones of a resin sample.

The direct contribution of mechanics on oxygen chemical reaction-diffusion phenomenon can be appreciated in equations (1) - (3) by the $\beta_{i} \nabla^{2}(\operatorname{tr} \mathbf{E})$ terms, in which the $\beta_{i}$ s represent coupling coefficients to be, eventually, identified.

All the evocated couplings are not easy to understand and to apprehend.

Reassuming, the main interaction phenomena investigated by the present research program are:

- the dependence of mechanical properties of the neat resin to the conversion of the chemical oxygen reaction-diffusion phenomenon,

- the eventual influence of strain on the oxidation rate,

- the effects of the oxygen pressure on the oxidation rate.

It should be noted that more details concerning the proposed models can be found in references [15-18,21]. Further theoretical and experimental research about the direct effects of mechanics on oxygen chemical reaction-diffusion phenomena is under development [22].

\section{3. "Model" materials}

The LIM-ENSAM laboratory elaborated two epoxy-aromatic diamine systems (DGEBA/DDS and DGEBA/Ethacure "model" materials close to the industrial epoxy matrix for their chemical composition) in order to study the effects of thermo-oxidation on the macromolecular network structure and on the viscoelastic/ mechanical properties, including fracture behaviour [17].

In fact, by varying the stoichiometry of the epoxy/amine ratio, it is possible to build degraded network models characterised by different crosslink densities and corresponding to stoichiometric networks having undergone a given number of chain scission.

For all these materials the curing cycles were optimized in order to achieve a maximum degree of crosslinking, to avoid further post curing effects which could distort the interpretation of results.

The results obtained both on the industrial matrix and on the matrix model DGEBA-DDS show that thermo-oxidation leads to a decrease in glass transition temperature, $T_{\mathrm{g}}$, which is due to a chain scission process induced by oxidation.

The observed change in $T_{\mathrm{g}}$ has been related to the number of chain scissions through the Di Marzio's law [19].

The modelled chain scissions have been then introduced into the mechanistic and kinetic schemes.

To explain the thermo-oxidation induced change of the elastic properties at room temperature, the following causal chain has been retained: thermo-oxidation may induce chain scissions which in turn may promote internal anti-plasticisation, which decreases the activity of the $\beta$ transition, leading ultimately to higher shear and the Young moduli values and to lower Poisson's ratio values. The phenomenon of thermo-oxidation induced anti-plasticisation has been well established experimentally by DMA tests. Fig. 1 shows schematically the effects of thermo-oxidation on the real $\left(\mathrm{E}^{\prime}\right)$ and the imaginary ( $\left.\mathrm{E}^{\prime \prime}\right)$ components of the Young's modulus as measured by DMA: at room temperature, the oxidized matrix exhibits values of $E^{\prime}$ which are higher than those measured on the virgin matrix.

Measurements of elastic modulus by ultra-micro indentation (UMI) confirmed this trend, both for the industrial epoxy resin and for the "model" resin with controlled number of chain scissions: for the industrial matrix, thermo-oxidation promotes the formation and growth of an oxidized layer exhibiting an elastic modulus gradient, whose local values are always higher than those of the virgin material. Similarly, toughness measurements on "model" epoxy networks have shown that toughness strongly decreases with increasing number of chain scission. However, at present, only phenomenological relations have been established between the observed changes in property and the structure of the network.

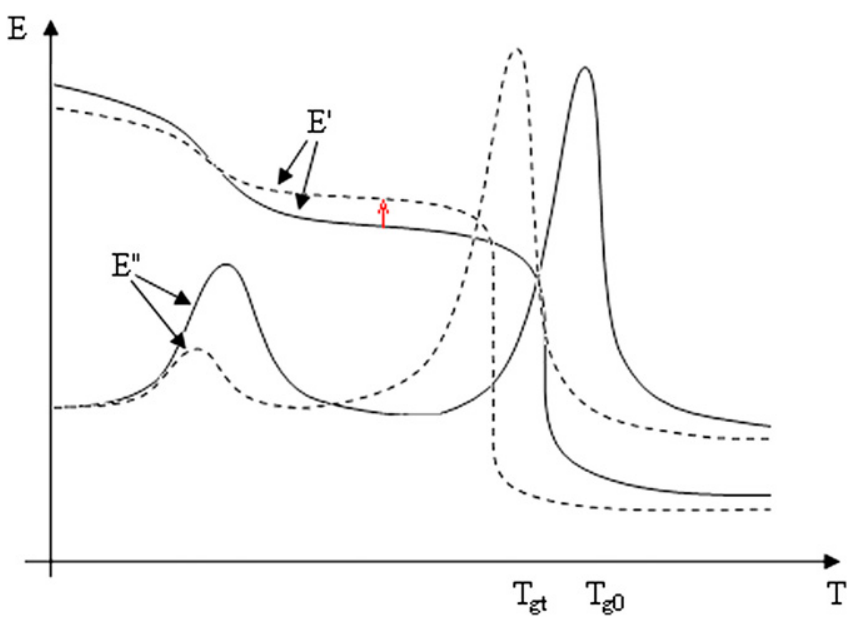

Fig. 1. Real ( $\left.E^{\prime}\right)$ and complex ( $\left.E^{\prime \prime}\right)$ part of the Young's modulus of a virgin (solid line) and oxidized (dotted line) epoxy network sample. The arrow shows the increase of $\mathrm{E}^{\prime}$ modulus in the glassy state. 

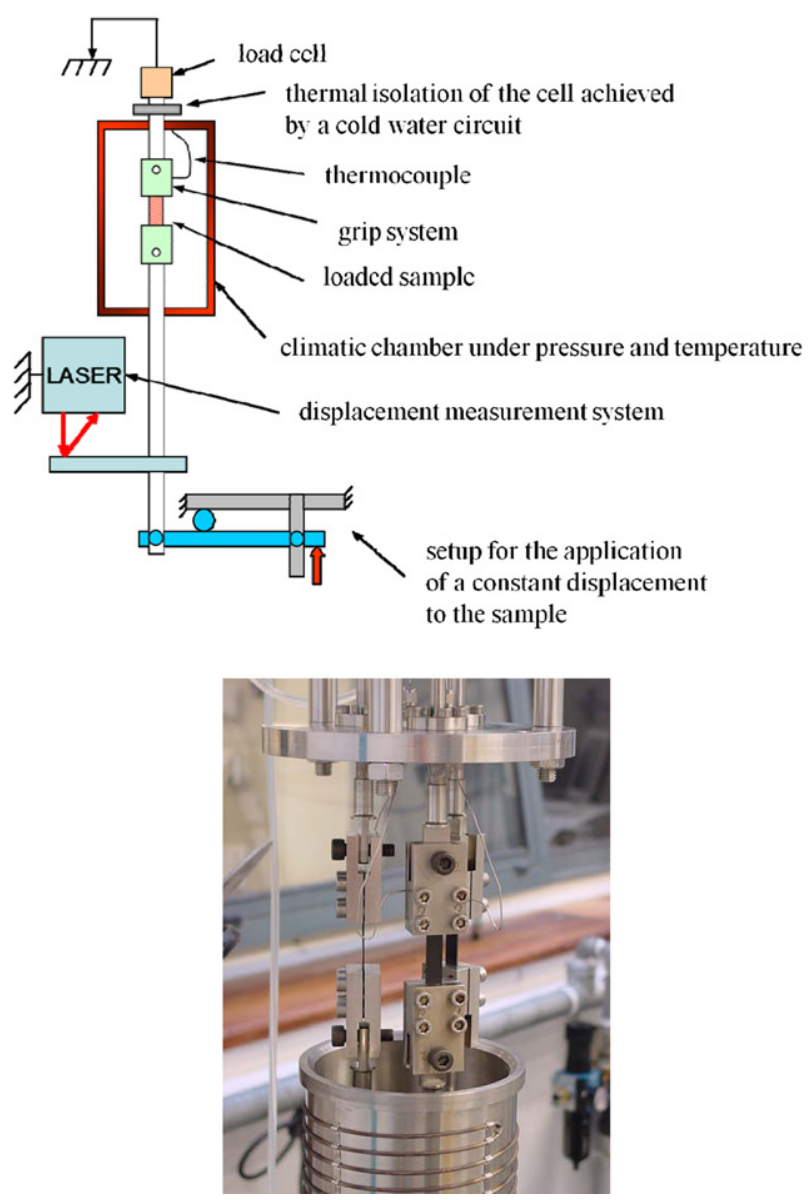

Fig. 2. Schematics and photographic image of the ENSMA COMEDI climatic chamber setup specifically developed for the thermo-oxidation testing of resin and composite samples.

\section{Industrial oxidized resin and couplings identification}

\subsection{COMEDI oxidative chambers}

In order to study experimentally the oxidation behaviour of polymers and composite samples subjected to mechanical stress in a thermo-oxidative environment, an oxidative chamber was conceived and manufactured at the ENSMA laboratory.

Inside the chamber, samples can be subjected to the combined effect of inert or oxidizing gas (up to 10 bar), temperature (up to $200{ }^{\circ} \mathrm{C}$ ) and load. The chamber consists of three separate and decoupled loading lines, each equipped with a thermocouple to be located on the sample, a load cell thermally insulated by a copper coil pipe containing a cold water flow and a remote displacement measurement system employing a system of laser sensors as illustrated in Fig. 2.

Each specimen is placed in a neutral or oxidizing environment under pressure, and subjected to an applied displacement: which is then adjusted by the laser measuring system in order to get the desired constant strain level. In order to assess the experimental scatter, three identical specimens can be simultaneously tested in the chamber. Finally, for each sample, pressure, temperature, displacement and load values are acquired in real time all through the test. The characterisation of the oxidation state of the material is then carried out by global (mass loss measures, DMA, DSC, resonance method) and local measures (ultra-micro indentation, UMI).

\subsection{Correlation between the elastic indentation modulus (EIT) and the concentration of oxidation products $(Q)$}

Industrial resin samples were aged at $150{ }^{\circ} \mathrm{C}$ under 5 bar pressure under both neutral and oxidizing environments for $18 \mathrm{~h}, 48 \mathrm{~h}$, $96 \mathrm{~h}$ and $430 \mathrm{~h}$ Fig. 3 shows the EIT distribution along sections of aged samples as a function of the distance from the sample free edge, for different ageing times and for the two different environments.

Under neutral environment (Fig. 3a), no significant EIT changes were observed with respect to the virgin resin. Therefore the mechanical loading alone is not able to affect the EIT of the industrial epoxy resin at $150^{\circ} \mathrm{C}$.

Under oxidizing environment (Fig. 3b) an increase in EIT is observed all along the oxidized layer (around $200 \mu \mathrm{m}$ thick). The thickness of such oxidized layer is comparable to that measured on samples aged under atmospheric air.

However, for samples oxidized under pressure the profile flattens near the edge of the sample along a distance lower than $50 \mu \mathrm{m}$. This effect can be related to the non-linear behaviour of the chemical reaction leading to saturation of the reaction rate under oxygen pressure increase.

This phenomenon was not observed in samples aged under atmospheric air for an equivalent oxidation time. This behaviour can be tentatively related to a non-linear pressure dependence of the oxygen solubility in the polymer.

The measured EITs and their spatial distribution were correlated to the concentration of grafted oxygen $(Q)$ profiles calculated with the reaction-diffusion model presented in Section 2.

Concerning the oxygen concentration at the surface of the sample $\left(C_{s}\right.$, boundary condition), a dual-mode sorption law was identified and employed (see, for instance, reference [20]):

$$
C_{s}=k_{\mathrm{d}} p+\frac{C_{\mathrm{H}}^{\prime} b p}{1+b p}
$$
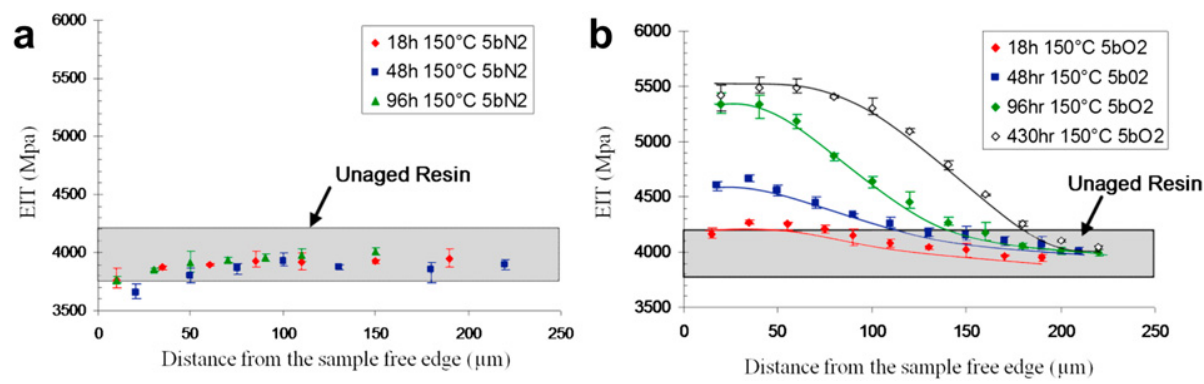

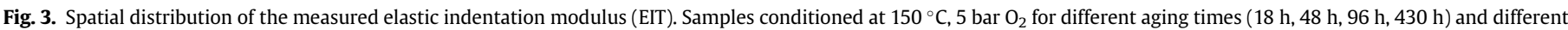
conditioning environments: neutral (a/pure nitrogen) or oxidizing (b/oxygen). The shaded areas represent the elastic modulus of the unaged resin. 

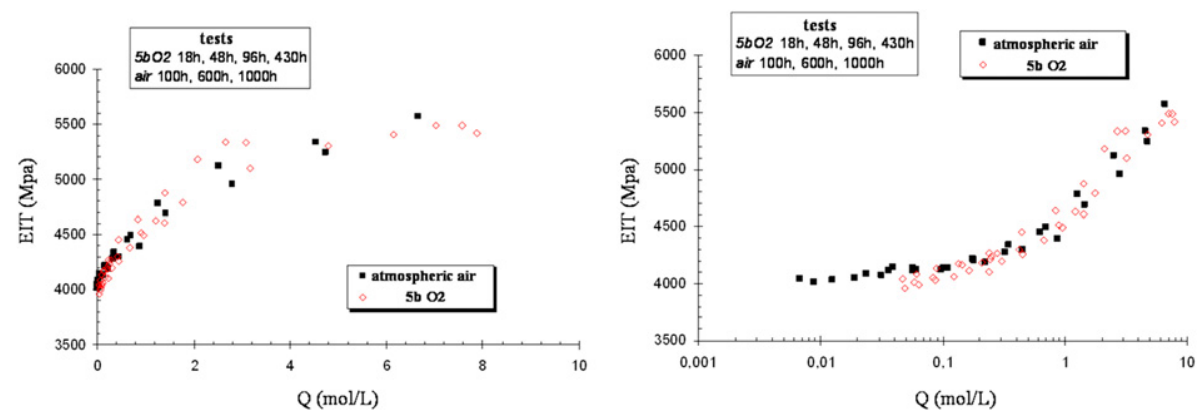

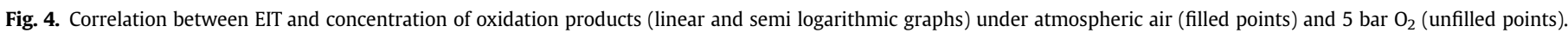

in which $p$ is the environment gas pressure and $k_{\mathrm{d}}$ is a solubilitylike coefficient to be identified (in the present study $\left.k_{\mathrm{d}}=0.03001 \mathrm{~mol} \mathrm{l}^{-1} \mathrm{bar}^{-1}\right) . C_{\mathrm{H}}^{\prime}$ and $b$ are two other parameters related to a Langmuir-type behaviour to be identified (in the present study $C_{\mathrm{H}^{\prime}}=0.0003 \mathrm{~mol} \mathrm{l}^{-1}$ and $b=0.848 \mathrm{bar}^{-1}$ ).

Fig. 4 shows the superposition of the experimental EIT measures and the concentration oxidation products $(Q)$ curves both obtained for samples aged under atmospheric air and 5 bar of pure oxygen.

All data belong to a unique low scattered curve having the following phenomenological form:

$$
\operatorname{EIT}(Q)=5510-1469 \exp (-0.48 Q)
$$

This phenomenological law expresses a physical mechanism relating the EIT to the $Q$ evolving values within the material. The existence of such a correlation for different values of pressure is a major result and is essential for the understanding of pressure accelerated thermo-oxidation phenomena.

\subsection{Effect of a strain gradient on oxygen reaction-diffusion}

In order to highlight the direct coupling appearing in the oxygen reaction-diffusion equation (the "tr $\mathbf{E}$ " term in equation (1)) thermo-oxidation tests were carried out on deformed specimens. The specimens are either straight or notched to generate strain gradients. The maximum applied displacement was chosen in order to achieve $70 \%$ of the failure load of the sample. For notched samples, simple elastic calculations show that stress/strain gradients are very marked (Fig. 5).

EIT profiles were measured along different directions, in oxidized zones characterised by high strain gradients (points 1,2 and 3 in Fig. 5) and very weak strain gradients (point 4 in Fig. 5). The differences between the measured values were within the experimental scatter. It appears thus that the effect of the strain gradient on the thermo-oxidation reaction-diffusion phenomenon is of the second order, and hence that this coupling can be neglected, at least for samples under pure tension.

\section{Behaviour of the oxidized ply}

Since the model parameters have been identified mainly by tests on neat virgin and oxidized resins the behaviour of the composite material is investigated by experimental/numerical research on composite samples.

In particular, two different phenomena are investigated, each at its pertinent scale:

- the local resin chemical shrinkage, its interaction with the surrounding fibres, the development of thermo-oxidation induced stress. The analysis is carried out at the microscopic scale (the scale of fibres and matrix); experimentally by confocal interferometric microscopy measures, numerically by simulations on a representative composite cell. This analysis allows validating the numerical tool and predicting the scenario of damage onset and propagation at the microscopic scale,

- the mass loss of a composite ply and of a composite laminate, the effect of anisotropy on the oxygen reaction/diffusion phenomenon. The analysis is carried out at the meso-macroscopic scale (the scale of a ply and of a laminate); experimentally, by mass loss measures on composite samples, numerically by mass loss predictions on the same structures. This analysis allows validating the numerical tool and putting
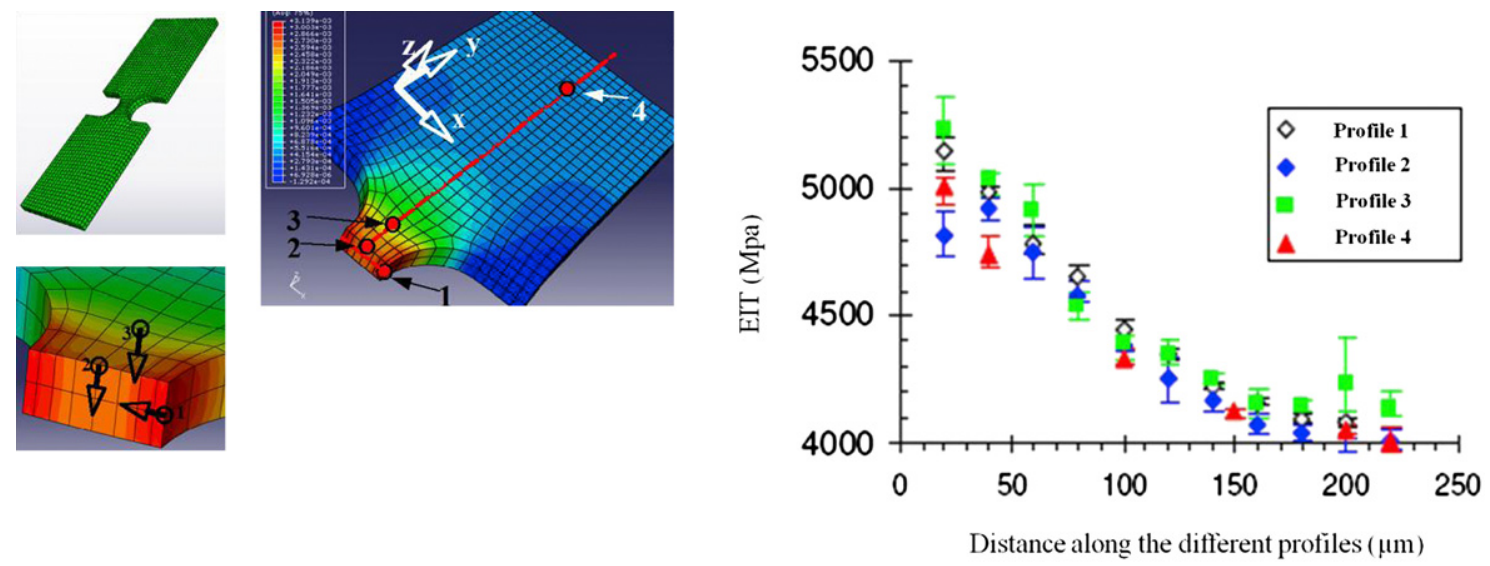

Fig. 5. Elastic indentation modulus profiles obtained by ultra-micro indentation tests on resin notched samples aged at $150{ }^{\circ} \mathrm{C}$ under 5 bar $\mathrm{O}_{2}$ under constant strain. 
forward reliable methods and strategies for accelerated ageing tests on composite materials and structures.

\subsection{Numerical tool}

A specific finite element (UEL within the ABAQUS ${ }^{\circledR}$ commercial finite element software) has been developed to simulate numerically the thermo-oxidation behaviour of the composite material (see reference [18] for further detail).

This is a hexahedral element, quadratic in displacement and concentration, and contains 27 integration points. Its degrees of freedom are the three displacements and the oxygen concentration, i.e. 4 degrees of freedom per node. The concentration values of the other chemical species that appear in the thermo-oxidation mechanistic scheme are stored in the table of state variables (SVAR) proposed by ABAQUS ${ }^{\circledR}$. The solution of the coupled set of differential equations of the mechanistic scheme is performed at each step by a Newton-Raphson technique.

The size of the time increments has been optimized to get good enough precision and stability of the procedure.

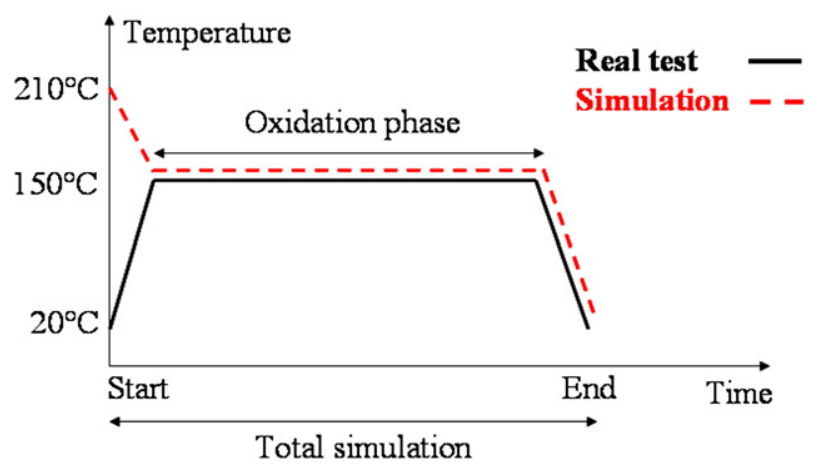

Fig. 7. Schematics of the loading history for numerical simulations following closely real test conditions.

\subsection{Experimental and numerical simulation of thermo-oxidation induced resin shrinkage in composite materials}

In Fig. 6b, the resin chemical shrinkage (maximum resin shrinkage depth) measured by interferometric confocal microscopy

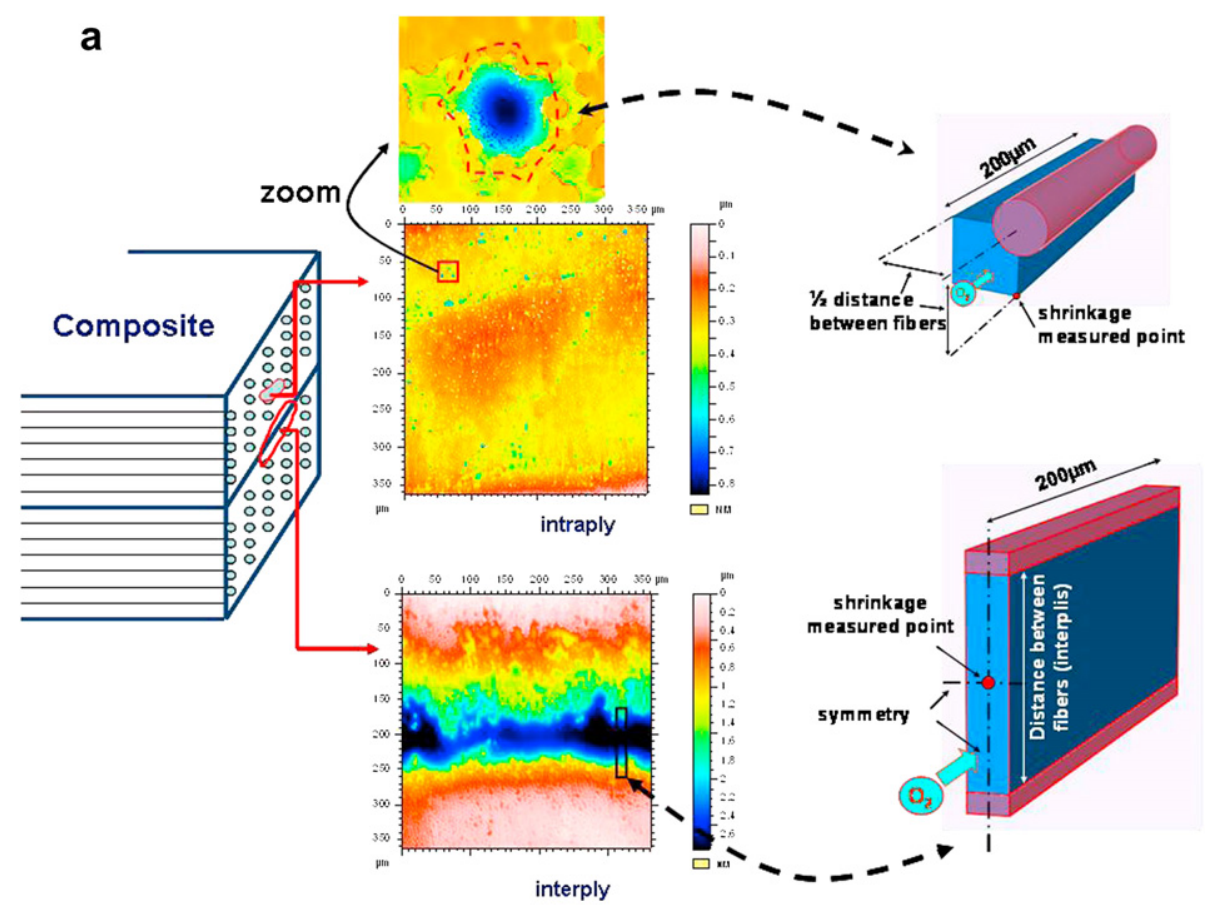

b

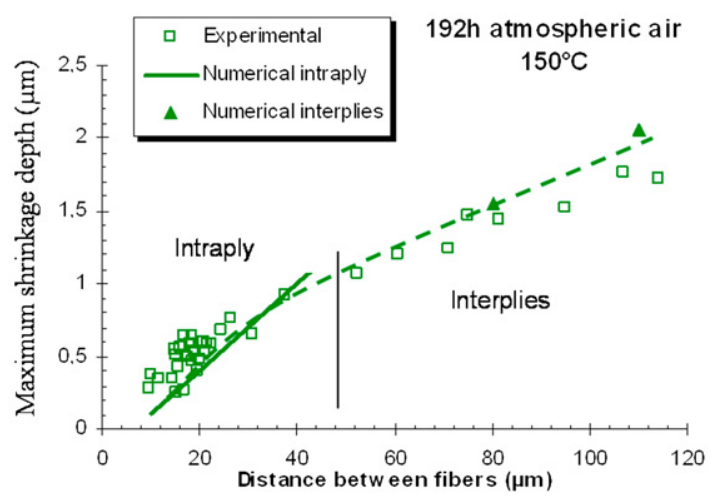

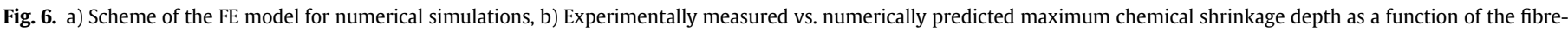
to-fibre distance in thermo-oxidized composites. 
in different configurations (intraply: between the fibres within one ply, or interply: between two distinct plies) are plotted as a function of the fibre-to-fibre distance: the greater this distance, the greater the matrix maximum shrinkage.
Based on such experimental results, two families of geometric models have been developed for numerical simulations (see Fig. 6a): the first represents a basic fibre/matrix square cell which is able to capture full 3D effects and is employed for intraply zones, a

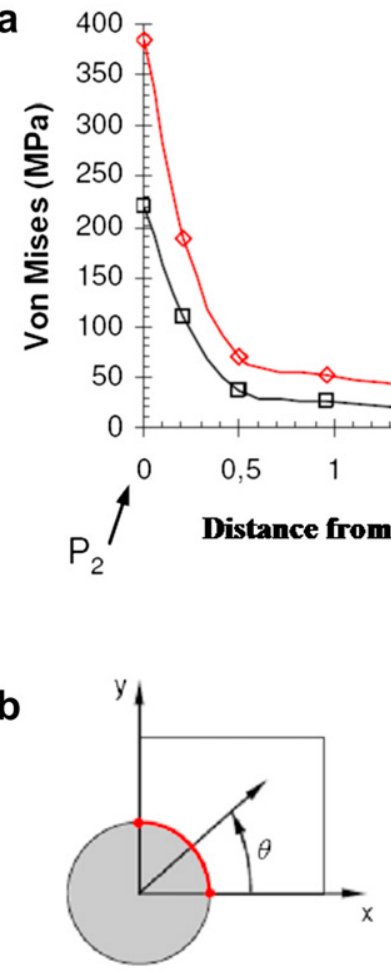

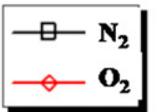

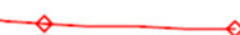

$1,5 \quad 2$

2,5

) m)
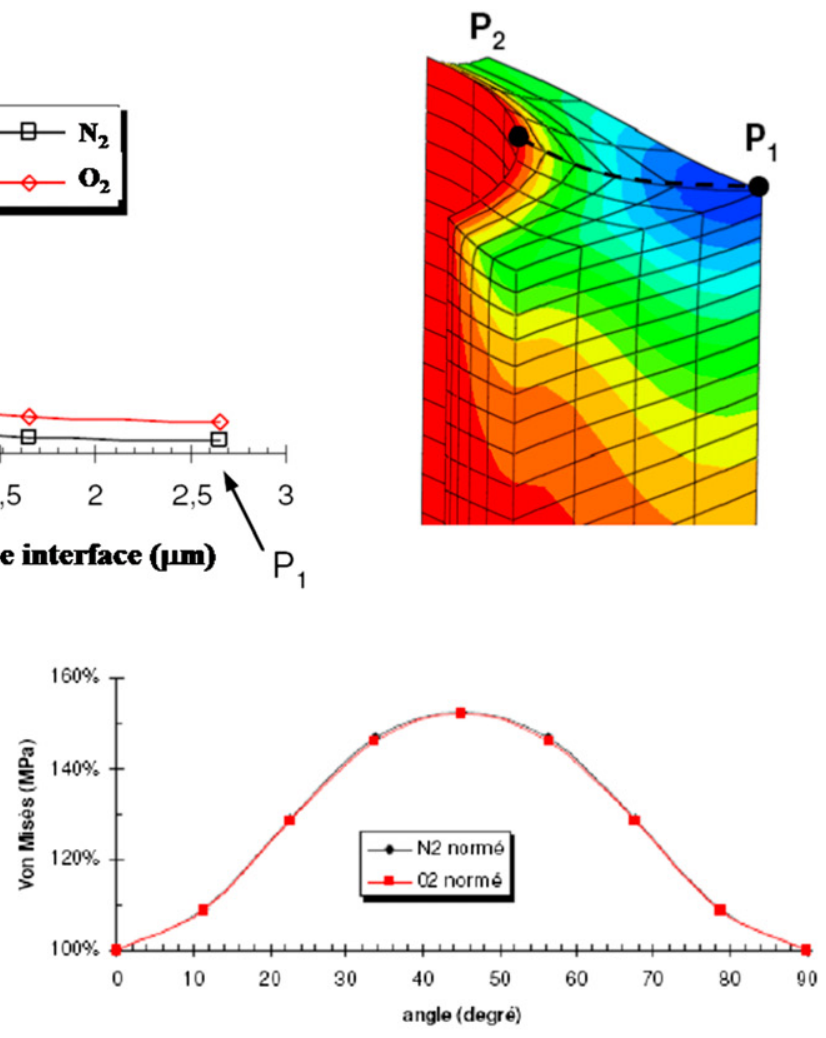

C

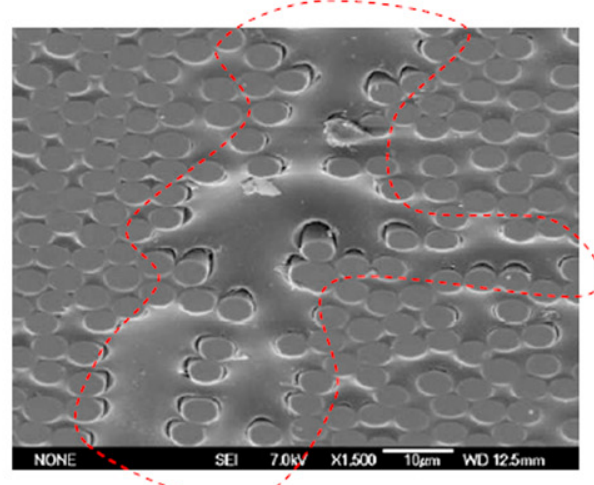

d

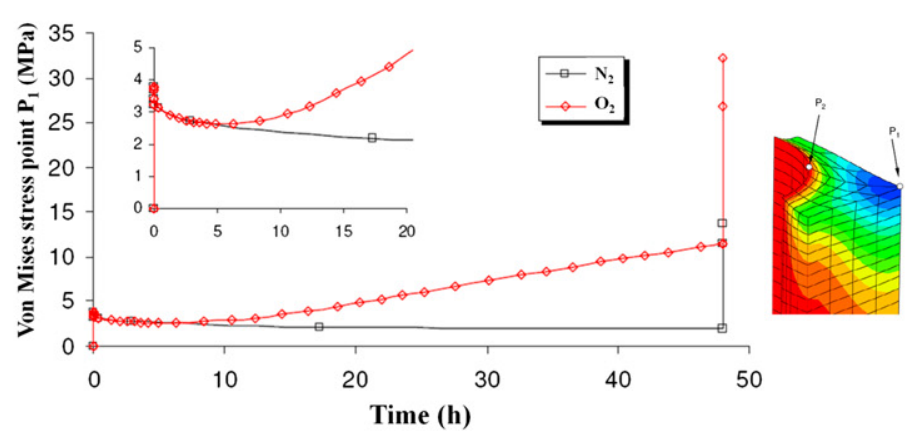

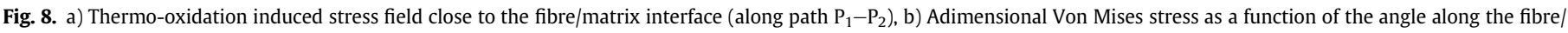
matrix interface, c) SEM images of fibre/matrix debonding, d) Time evolution of Von Mises stress in the representative cell (point $\mathrm{P}_{1}$ ). 
the second one represents interply zones and simulates the 2D plane strain effects which are felt across such zones.

The coupled reaction-diffusion-mechanics equations are then solved for the two configurations applying a load history which reproduces the real experimental thermo-mechanical solicitation (Fig. 7).

Fig. 6b shows that a very good agreement is found between confocal interferometric microscopy resin shrinkage measures (open squares) and simulation results (intraply zones (solid line) and interplay zones (filled green triangles)), validating the predictive power of the approach.

\subsection{Damage onset}

Once the model is validated, a numerical study about the thermo-oxidation induced stress field in composite materials is carried out. It has to be noted that simulations take into account the thermal stress due to the cooling from the composite cure temperature to room temperature and related to the different thermal expansion coefficients of fibres and matrix (see Fig. 7).

Fig. 8a illustrates the von Mises stress near a fibre/matrix interface (along path $\mathrm{P}_{1}-\mathrm{P}_{2}$ ) for a composite exposed to neutral $\left(\mathrm{N}_{2}\right)$ and oxidizing $\left(\mathrm{O}_{2}\right)$ environment and shows - for both environments - the existence of a stress gradient and stress singularity at the intersection between the interface and the free edge.

Despite the singularity, the stress levels are consistently higher for composites under oxidizing environment $\left(\mathrm{O}_{2}\right)$.

For both environments the adimensional Von Mises stress (with respect to its value at $\theta=0$ ) is plot in Fig. $8 \mathrm{~b}$ as a function of the angle $\theta$ along the fibre/matrix interface at the free edge; the maximum stress level is achieved for $\theta=45^{\circ}$, that is, when the fibre-to-fibre distance is maximum.

This prediction is fully consistent with scanning electron microscopy images (Fig. 8c), which show that the majority of fibre/ matrix interface debonding takes place in matrix rich areas, for higher fibre-to-fibre distance values.

Fig. 8d shows the time evolution of Von Mises stress at point $P_{1}$, both for neutral and oxidizing environment.

In particular, the thermo-oxidation induced chemical shrinkage strain contributes significantly to the stress development of composites under oxidizing environment.

Moreover, while the Von Mises stress of samples under neutral environment keeps relaxing at high temperature due to the viscoelastic behaviour of the resin, this is not so for samples under oxidizing environments. In fact, in this case, thermo-oxidation induced chemical shrinkage stress is picked up by the sample and increases with time. Therefore at the end of the process, following thermal cooling to room temperature, the Von Mises stress is significantly higher in samples under oxidizing environment.

Table 1

Sample configurations for mass loss testing.

\begin{tabular}{|c|c|c|c|c|c|c|c|}
\hline \multirow[t]{2}{*}{ Sample } & \multirow[t]{2}{*}{$\begin{array}{l}\text { Total } \\
\text { surface } \\
\left(\mathrm{mm}^{2}\right)\end{array}$} & \multicolumn{2}{|c|}{$\begin{array}{l}\text { Fibres parallel } \\
\text { to the surface }\end{array}$} & \multicolumn{2}{|c|}{$\begin{array}{l}\text { Fibres } \\
\text { perpendicular } \\
\text { to the surface }\end{array}$} & \multicolumn{2}{|c|}{$\begin{array}{l}\text { Fibres: } 45^{\circ} \text { with } \\
\text { respect to the } \\
\text { surface }\end{array}$} \\
\hline & & $\begin{array}{l}\text { Surface } \\
\left(\mathrm{mm}^{2}\right)\end{array}$ & $\%$ & $\begin{array}{l}\text { Surface } \\
\left(\mathrm{mm}^{2}\right)\end{array}$ & $\%$ & $\begin{array}{l}\text { Surface } \\
\left(\mathrm{mm}^{2}\right)\end{array}$ & $\%$ \\
\hline A & 7040 & 6800 & 96.6 & 240 & 3,4 & 0 & 0 \\
\hline B & 7040 & 1040 & 14.8 & 6000 & 85,2 & 0 & 0 \\
\hline $\mathrm{C}$ & 7040 & 800 & 11.4 & 0 & 0 & 6240 & 88,6 \\
\hline D & 7040 & 6800 & 96.6 & 240 & 3,4 & 0 & 0 \\
\hline $\mathrm{E}$ & 7040 & 6240 & 88.6 & 800 & 11,4 & 0 & 0 \\
\hline $\mathrm{F}$ & 7040 & 6000 & 85.2 & 0 & 0 & 1040 & 14,8 \\
\hline
\end{tabular}

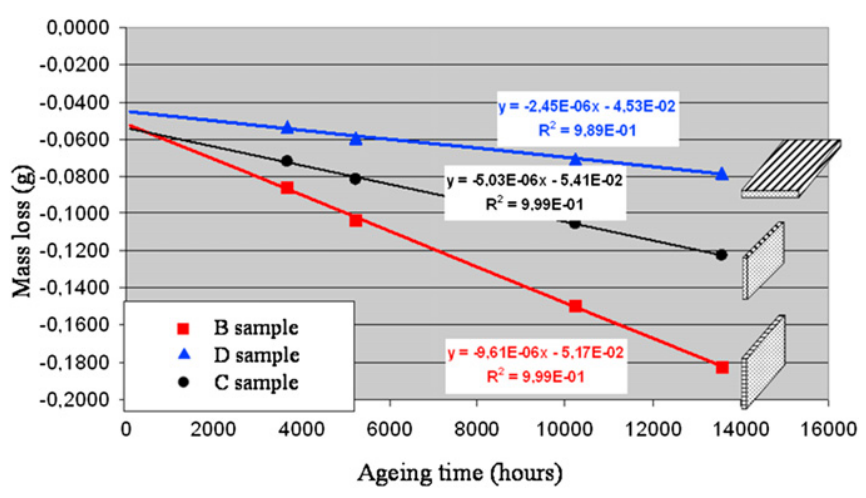

Fig. 9. Experimentally measured mass loss for D, B and C samples (see Table 1).

\subsection{Mass loss, anisotropy effects}

High temperature long-term conditioning tests leading to thermo-oxidation degradation have been performed by EADS IW in order to estimate the global mass loss of CFRP composite samples with different stacking sequences. Mass loss measures can be seen as a global indicator of oxidative degradation.

The different sample configurations are presented in Table 1 . The geometry is the same for all samples $(100 \mathrm{~mm} \times 30 \mathrm{~mm} \times 4 \mathrm{~mm})$ therefore the surface exposed to the oxidative environment is identical.

Type $B$ specimens have the highest proportion of fibres perpendicular to the sample surface (85.2\%) while type A, D, E and $\mathrm{F}$ specimens the lowest (between $0 \%$ and $3.4 \%$ ). For configuration $C$ the sample exhibits a high proportion of fibre with an angle of $45^{\circ}$ with respect to the external surface (88.6\%). Prior to testing specimens were dried in an oven at $70{ }^{\circ} \mathrm{C}$ under vacuum - desorption was characterised by mass loss measures. The specimens were then subjected to thermal ageing at $120{ }^{\circ} \mathrm{C}, 150{ }^{\circ} \mathrm{C}$ and $180{ }^{\circ} \mathrm{C}$ under atmospheric air environment.

Three samples per configuration were tested.

Fig. 9 shows - for instance - the mass loss (in grams) at $150{ }^{\circ} \mathrm{C}$ as a function of the ageing time up to $14,000 \mathrm{~h}$ - about 600 days of ageing - for three configurations, D, B and C.

Fig. 9 shows that the mass loss rate depends strongly on the fibre orientation with respect to the exposed surface, sample B leading to much fast oxidation than sample $\mathrm{D}$, the behaviour of the C sample was somewhere between the two.

This result, confirmed by tests at $180{ }^{\circ} \mathrm{C}$, demonstrates the anisotropic nature of thermo-oxidation phenomena in composite

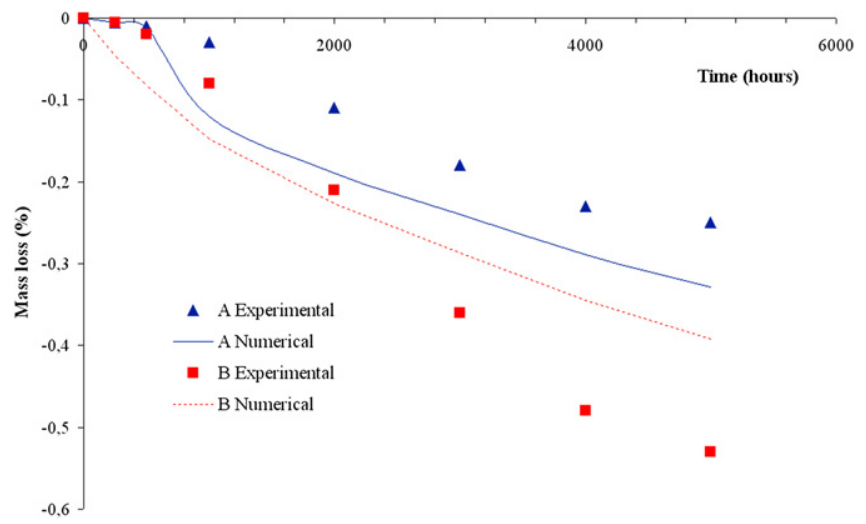

Fig. 10. Experimentally measured vs. numerically simulated mass loss for two sample configurations, A: fibres parallel to the exposed surface, B: fibres perpendicular to the exposed surface; point: experimental, lines: numerical. 

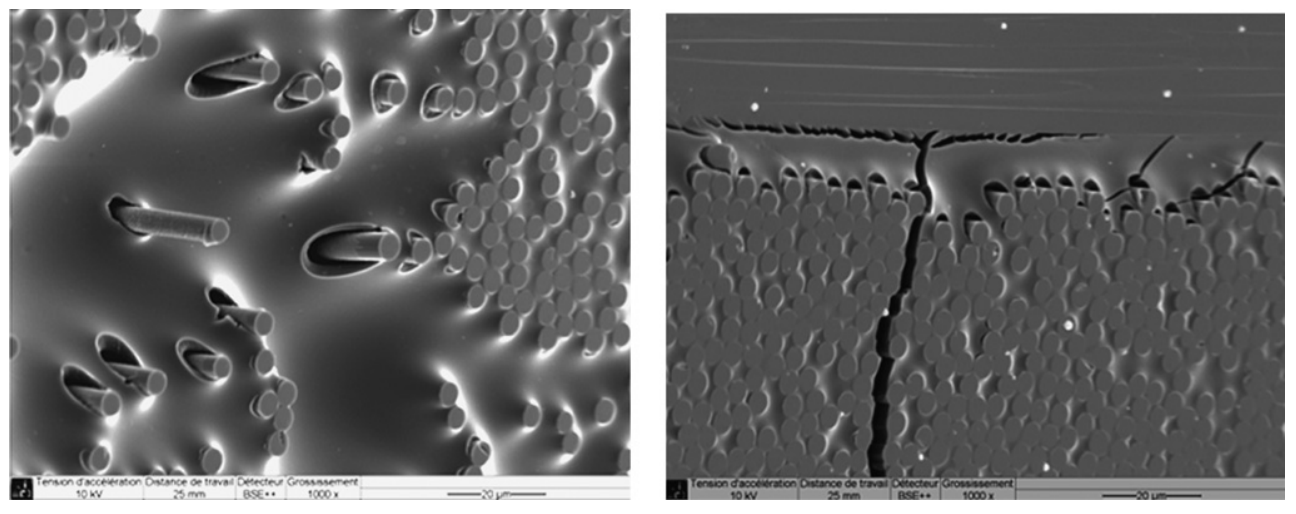

Fig. 11. SEM images of surface damage observed in thermo-oxidized composite samples $\left(100 \mathrm{~h}\right.$ at $150{ }^{\circ} \mathrm{C}$ under 5 bar $\left.\mathrm{O}_{2}\right)$.

samples, therefore the effect of anisotropy should be taken into account in a predictive model.

The ageing behaviour of samples $\mathrm{A}$ and $\mathrm{B}$ at $150{ }^{\circ} \mathrm{C}$ under atmospheric air environment has been simulated by the numerical model implemented in ABAQUS ${ }^{\circledR}$. The diffusion constant for the composite are respectively $D_{11}=D_{\text {resin }}=1.3 \mu \mathrm{m}^{2} / \mathrm{s}$ in the fibre direction and $\mathrm{D}_{22}=\mathrm{D}_{33}=0.8 \mu \mathrm{m}^{2} / \mathrm{s}$ in the direction transverse to the fibres [18]. Only $5000 \mathrm{~h}$ of ageing were simulated. The simulated mass loss values are compared to the experimental ones in Fig. 10.

We note that the model well reproduces the trend of the experiments.

In particular, the mass loss curves simulated for sample B are very close to the experimental ones up to $2000 \mathrm{~h}$ and tend to diverge thereafter. This finding has to be related to the observation of some interlaminar matrix cracks appearing on the oxidized surfaces of sample B (starting from $1000 \mathrm{~h}$ ) and whose number increases thereafter.

The creation of new surfaces for oxygen ingress could explain the differences between experimental and simulated mass loss; in its present version, the model does not take into account the phenomenon of damage onset and growth in composite laminates.

The comparison between experiment and simulation is less good for sample A, for which no damage was observed along the same time ageing range. The experimental and numerical simulated values have, however, the same order of magnitude.

\section{Conclusions}

The main aims of the COMEDI research program have been achieved.

A mechanistic model for thermo-oxidation for an epoxy matrix has been developed then validated at both microscopic and macroscopic scales. The research included the development of the following input steps:

- Development and identification of a general kinetic mechanistic scheme for matrix oxidation,

- Better understanding of the structure/property relationships for thermo-oxidized epoxy networks,

- Development of a theoretical coupled model including the laws for diffusion controlled thermo-oxidation, resin chemical shrinkage/stress build-up and viscoelastic behaviour of the epoxy matrix,

- Development of the COMEDI experimental setup, a set of climatic chambers allowing for the accelerated thermo-oxidative testing of composite samples under stress at relatively high pressure,
- Development of a dedicated numerical tool and its implementation in the commercial FE software ABAQUS ${ }^{\circledR}$.

Experimental validation of the developed models was provided at very different scales, on pure polymer matrix and on composite laminate samples.

Further understanding of the oxygen reaction/diffusion process along a composite sample is needed; the role of anisotropy needs to be better clarified and most of all, the coupling between diffusion and damage needs to be addressed (Fig. 11).

\section{References}

[1] Magendie F, Seferis J, Aksay I. Thermal stability comparison of ceramic and carbon fiber BMI matrix composites. Proceeding of International SAMPE 1990;35(2):2280-8.

[2] Parvatareddy H, Wang JZ, Lesko JJ, Dillard DA, Reifsnider KL. An evaluation of chemical aging/oxidation in high-performance composites using the Vickers micro-indentation technique. Jornal of Computational Materials 1996;30 (2):210-30.

[3] Madhukar M, Bowles KJ, Papadopoulos DS. Thermo-oxidative stability and fiber surface modification effects on the in-plane shear properties of graphite/ PMR 15 composites. Jornal of Computational Materials 1997;31(6):596-618.

[4] Scola D. A study of the thermo-oxidation process and stability of graphite and glass/PMR polyimide composites. In: Proceedings of the joint U.S.-Italy symposium on composite materials, Capri, Italy, June 15-19, 1981. New York: Plenum Press; 1983. pp. 159-169.

[5] Hashin Z, Jones M, Cassin T. Thermo-mechanical analysis of oxidation protected carbon-carbon composites. Nasa Reports AD-A268191. Materials Sciences Corp, (Blie Bell, PA, United States); 1993.

[6] Bowles K. Predicting the durability of PMR15 composites aged at elevated temperatures. In: Proceeding of Duracosys99, Bruxelles, 11-14 Juillet, 1999.

[7] Tandon GP, Pochiraju KV, Schoeppner GA. Thermo-oxidative behavior of hightemperature PMR-15 resin and composites. Materials Science and Engineering: A 2008;498:150-61.

[8] Pochiraju KV, Tandon GP, Schoeppner GA. Evolution of stress and deformations in high temperature polymer matrix composites during thermo-oxidative aging. Mechanics of Time Dependent Materials 2008:12:45-68.

[9] Lafarie-Frenot MC, Rouquié S. Influence of oxidative environments on damage in $\mathrm{C} /$ Epoxy laminates subjected to thermal cycling. Composites Science and Technology 2004;64(10-11):1725-35.

[10] Colin X, Verdu J. Vieillissement thermooxydant des composites à matrice organique. Rev Comp Mat Av 2002;12:63-186.

[11] Colin X, Marais C, Verdu J. Kinetic modelling and simulation of gravimetric curves. Application to the oxidation of polybismaleimides and epoxy resins. Polymer Degradation and Stability 2002;78:545.

[12] Colin X, Verdu J. Strategy for studying thermal oxidation of organic matrices. Journal of Computer Science and Technology 2005;65:411.

[13] Lafarie-Frenot MC, Rouquie S, Ho NQ Bellenger V. Comparison of damage development in C/epoxy laminates during isothermal ageing or thermal cycling. Composites Part A: Applied Science and Manufacturing 2006;37 (4):662-71.

[14] Rambert G, Jugla G, Grandidier JC, Cangémi L. A modelling of the direct couplings between heat transfer, mass transport, chemical reactions and mechanical behaviour, numerical implementation to explosive decompression. Composites Part A 2006;37:571-84.

[15] Olivier L, Ho NQ Grandidier JC, Lafarie-Frenot MC. Characterization by ultramicro indentation of an oxidized epoxy polymer: correlation with the 
predictions of a kinetic model of oxidation. Polymer Degradation and Stability 2008;93:489-97.

[16] Olivier L, Baudet C, Bertheau D, Grandidier JC, Lafarie-Frenot MC. Development of experimental, theoretical and numerical tools for studying thermo-oxidation of CFRP composites. Composites Part A 2009;40: $1008-16$.

[17] Rasoldier N, Colin X, Verdu J, Bocquet M, Olivier L, Chocinski-Arnault L, et al. Model systems for thermo-oxidised epoxy composite matrices. Composites Part A: Applied Science and Manufacturing 2008;39:1522-9.

[18] Olivier L. PhD Thesis, in French, LMPM-ENSMA, 2008.
[19] Gibbs JH, DiMarzio EA. Journal of Chemical Physics 1958;28:373.

[20] Klopffer MH, Flaconneche B. Transport properties of gases in polymers: bibliographic review. Oil and Gas Science and Technology - Rev IFP 2001;56:223-44.

[21] Gigliotti, M., Olivier, L., Vu, D.Q., Grandidier, J.C., Lafarie-Frenot, M.C. Local Shrinkage and Stress Induced by Thermo Oxidation in Composite Materials at High Temperatures, submitted for publication.

[22] Gigliotti M., Grandidier J.C. Chemo-Mechanics Couplings in Polymer Matrix Materials Exposed to Thermo-Oxidative Environments. Comptes Rendus Mécanique, in press, doi:10.1016/j.crme.2010.02.008. 